\title{
RESIDUAL LIFE PREDICTION FOR HIGHLY RELIABLE PRODUCTS WITH PRIOR ACCELERATED DEGRADATION DATA
}

\section{PROGNOZOWANIE TRWAŁOŚCI RESZTKOWEJ WYSOCE NIEZAWODNYCH PRODUKTÓW NA PODSTAWIE DANYCH HISTORYCZNYCH Z PRZYSPIESZONYCH BADAŃ DEGRADACJI}

\begin{abstract}
To precisely predict the residual life for functioning products is a key of carrying out condition based maintenance. For highly reliable products, it is difficult to obtain abundant degradation data to precisely predict the residual life under normal stress levels. Thus, how to make use of historical degradation data to improve the accuracy of the residual life prediction is an interesting issue. Accelerated degradation testing, which has been widely used to evaluate the reliability of highly reliable products, can provide abundant accelerated degradation data. In this paper, a residual life prediction method based on Bayesian inference that takes accelerated degradation data as prior information was studied. A Wiener process with a time function was used to model degradation data. In order to apply the random effects of all the parameters of a Wiener process, the non-conjugate prior distributions were considered. Acceleration factors were introduced to convert the parameter estimates from accelerated stress levels to normal stress levels, so that the proper prior distribution types of the random parameters can be selected by the Anderson-Darling statistic. A Markov Chain Monte Carlo method with Gibbs sampling was used to evaluate the posterior means of the random parameters. An illustrative example of self-regulating heating cable was utilized to validate the proposed method.
\end{abstract}

Keywords: Residual life; Bayesian inference; random parameters; Wiener process; acceleration factor.

\begin{abstract}
Precyzyjne przewidywanie trwatości resztkowej użytkowanego produktu stanowi klucz do prawidlowego utrzymania ruchu $w$ oparciu o bieżący stan techniczny (condition-based maintenance).W przypadku produktów o wysokiej niezawodności, trudno jest uzyskać ilość danych degradacyjnych, która umożliwiałaby precyzyjne prognozowanie trwałości resztkowej przy normalnym poziomie obciażeń. Dlatego też bardzo ważnym zagadnieniem jest wykorzystanie historycznych danych degradacyjnych umożliwiających zwiększenie trafności prognozowania trwałości resztkowej. Przyspieszone badania degradacyjne, które powszechnie wykorzystuje się do oceny niezawodności wysoce niezawodnych produktów, moga dostarczać bogatych danych o przyspieszonej degradacji. W przedstawionej pracy badano metode prognozowania trwatości resztkowej oparta na wnioskowaniu bayesowskim, w którym jako uprzednie informacje wykorzystano dane z przyspieszonych badań degradacji. Dane degradacyjne modelowano za pomoca procesu Wienera z funkcją czasu. Aby móc zastosować efekty losowe wszystkich parametrów procesu Wienera, rozważano niesprzężone rozklady a priori. Wprowadzono wspótczynniki przyspieszenia, które pozwolity na przekształcenie szacowanych wartości parametrów z poziomu obciążéstosowanych w próbie przyspieszonej do poziomu obciążé normalnych, co umożliwiło wybór odpowiednich typów parametrów losowych rozkładu a priori zwykorzystaniem statystyki testowej Andersona-Darlinga. Metodę Monte Carlo oparta na łańcuchach Markowa z próbnikiem Gibbsa wykorzystano do oceny średnich a posteriori parametrów losowych. Proponowana metodę zweryfikowano na postawie przyktadu samoregulującego przewodu grzejnego.
\end{abstract}

Slowa kluczowe: trwałość resztkowa; wnioskowanie bayesowskie; parametry losowe; proces Wienera; wspótczynnik przyspieszenia.

\section{Introduction}

Recently, more and more highly reliable products have emerged in military and aerospace fields. However, it is very time-consuming to obtain enough failure data to evaluate the reliability of highly reliable products under normal stress levels. To resolve this problem, accelerated life test (ALT) is widely adopted to obtain product failure data in an acceptable time period. But for highly reliable products, even accelerated life test is not effective because little failure data can be obtained within limited time and budget. For some highly reliable product, their certain performance indexes will degrade over time. If the performance degradation can be observed, product lifetime information is likely to be extrapolated. Therefore, accelerated degradation test (ADT), under which products are put into accelerated stress levels to accelerate degradation process, has become a popular approach to the lifetime prediction for highly reliable products $[13,21,26,32,33]$. However, the aim of ADT is to extrapolate the lifetime information for the population rather than the residual life for an individual.

The residual life of a product is defined as the length from the current time to the failure time, and precisely predicting the residual life is important to carry out condition based maintenance (CBM), and prognostics and health management $[1,22]$. For an individual with high reliability, the degradation data observed under normal stress levels cannot show a distinct degradation trend, therefore it is difficult to precisely predict the residual life. In order to precisely predict the residual life for an individual with limited real-time degradation data, the prediction methods based on Bayesian inference have been popularly studied [3, 7, 8]. Gebraeel et al [5] developed an exponential degradation model with random parameters to model bearing degradation signals. They assumed the random parameters to obey conjugate prior 
distributions for mathematical tractability, and obtained the prior distributions of random parameters using the historical degradation data of the population of devices, then predicted the residual life for an individual with the real-time degradation data. Chakraborty et al [2] also studied the exponential degradation model with random parameters, but they assumed the random parameters to obey non-conjugate prior distributions, and adopted the Metropolis-Hasting algorithm to estimate the posterior means of random parameters. Gebraeel et al [6] proposed a Bayesian method, which takes the failure time data as historical information while takes the real-time degradation data of an individual as filed information, to predict the residual life distribution for a rotating machinery. Karandikar et al [10] developed a Bayesian method, which applied Monte Carlo simulations to evaluate the posterior means of random parameters, to predict the residual life for an aircraft fuselage panel. Baraldi et al [1] also developed a Bayesian method, which combines the degradation data of historical equipment and the real-time observing degradation data, to predict the residual life for nuclear power plants. Jin et al [9] presented a Bayesian framework based on a Wiener process with random parameters. The framework utilizes off-line population degradation data and on-line individual degradation data to predict residual life. Wang et al [28] also studied the Bayesian method based on Wiener degradation processes.

From the above analysis, it can be concluded that the residual life prediction methods based on Bayesian inference usually take the historical degradation data or failure data under normal stress levels as prior information. However, there is a lack of research on how to use accelerated degradation data as prior information. For some high reliable products, the accelerated degradation data is the only prior information source. Thus, how to make full use of historical accelerated degradation data to predict residual life is an interesting and significant issue. In the paper, we proposed a Bayesian method, which takes accelerated degradation data as prior information while considers the real-time degradation data observed under normal stress level as field information, to improve the prediction accuracy of the residual life for a highly reliable product.

The rest of the paper is organized as follows: Section 2 describes the residual life prediction model based on a Wiener process with random parameters. Section 3 discusses how to evaluate the prior distributions of the random parameters from accelerated degradation data. We deduced the expression of the acceleration factor based on Wiener degradation process, and converted parameter estimates from accelerated stress levels to normal stress level through acceleration factors. Section 4 develops simulation tests to validate the proposed method of converting parameter estimates. Section 5 provides a case study of self-regulating heating cable to investigate the effectiveness of the proposed Bayesian method. Section 6 draws some conclusions.

\section{Residual life prediction model}

It is well known that the main characteristic of degradation process is uncertain over time, therefore stochastic process models, such as Wiener process, Gamma process, Poisson process, et al, are naturally appropriate to model the evolution of degradation process. Wiener process can characterize both monotonic and non-monotonic degradation data, and describe unit-to-unit variance of products if random parameters are considered. Hence, Wiener process has been widely applied to model stochastic degradation process, see Whitmore and Schenkelberg [31], Wang [29], Peng and Tseng [19], Wang et al [30], Huang et al [4].

In mathematics, a Wiener process $\{X(t)=\mu \cdot \Lambda(t)+\sigma \cdot B(\Lambda(t))\}$ has independent increments $\Delta X(t)=X(t+\Delta t)-X(t)$ that follow a normal distribution as:

$$
\Delta X(t) \sim \mathrm{N}\left(\mu \Delta \Lambda(t), \sigma^{2} \Delta \Lambda(t)\right)
$$

where $\mu$ is a drift parameter, $\sigma(\sigma>0)$ is a diffusion parameter, $\Lambda(t)$ is a monotone increasing function of time $t$ with $\Lambda(0)=0$, $\Delta \Lambda(t)=\Lambda(t+\Delta t)-\Lambda(t)$ denotes a time increment and $B(\cdot)$ denotes a standard brown motion.

Let a constant value $l$ represent the failure threshold, the failure time $\xi$ can be considered to be the time when $X(t)$ firstly reaches $l$. So the failure time $\xi$ can be described as:

$$
\xi=\inf \{t: X(t) \geq l\}
$$

For a Wiener process, it is well known that the failure time $\xi$ follows an inverse Gaussian distribution. So the probability density function (PDF) of $\xi$ can be expressed as:

$$
f_{\xi}(t)=\frac{l}{\sqrt{2 \pi \sigma^{2} \Lambda^{3}(t)}} \exp \left[-\frac{(l-\mu \Lambda(t))^{2}}{2 \sigma^{2} \Lambda(t)}\right] \frac{\mathrm{d} \Lambda(t)}{\mathrm{d} t}
$$

Given that the degradation $X\left(t_{i}\right)$ at time $t_{i}$ does not reaches $l$, the residual life $R L_{t_{i}}$ at $t_{i}$ can be defined as $R L_{t_{i}}=\inf \left\{t: X\left(t_{i}+t\right) \geq l \mid X\left(t_{i}\right)<l\right\}[7,24]$. Therefore, the PDF of $R L$ can be written as:

$$
f_{R L}(t)=\frac{l^{\prime}}{\sqrt{2 \pi \sigma^{2}(\Lambda(t))^{3}}} \exp \left[-\frac{\left(l^{\prime}-\mu \Lambda(t)\right)^{2}}{2 \sigma^{2} \Lambda(t)}\right] \frac{\mathrm{d} \Lambda(t)}{\mathrm{d} t}
$$

where $l^{\prime}=l-X(t)$. Furthermore, the expectation of $R L$ can be deduced from:

$$
\overline{R L}=\mathrm{E}(R L)=\int_{0}^{+\infty} t \cdot f_{R L}(t) \mathrm{d} t
$$

where $\Lambda^{-1}(\cdot)$ denotes the inverse function of $\Lambda(\cdot)$. In order to obtain better flexibility and tractability, the form of $\Lambda(\cdot)$ was specified as

$\Lambda(t)=t^{r}$. If $r=1$, it is appropriate to model linear degradation processes. If $r>1$, it is able to model convex degradation processes. If $r<1$, it is capable of modeling concave degradation processes.

Thus, the RL can be evaluated once the estimates of $\mu, \sigma, r$ are obtained. However, the real-time degradation data of highly reliable product is commonly so little not to be straightforward used to obtain credible estimates $\hat{\mu}, \hat{\sigma}, \hat{r}$. To resolve the problem, we adopted a Bayesian method to obtain more credible posterior estimates of $\hat{\mu}, \hat{\sigma}, \hat{r}$ by making full use of historical accelerated degradation data. Although the application of Wiener processes in Bayesian inference has been widely studied in literature, most works assume that the random parameters of a Wiener process obey the following conjugate prior distributions: $\sigma^{2} \sim \mathrm{IG}(a, b), \mu \mid \sigma^{2} \sim \mathrm{N}\left(c, d \cdot \sigma^{2}\right)$, where $\mathrm{IG}(\cdot)$ represents an Inverse Gamma distribution, and $a, b, c, d$ are hyper parameters. The above assumption has two limitations. First, the random effect of $r$ can not be taken into account; Second, $\mu, \sigma$ are limited to 
obey the above specified distributions, which may not be applicable to some cases. In this paper, the non-conjugate prior distributions of $\mu, \sigma, r$ are alternatively used in Bayesian inference, and $\mu, \sigma, r$ are assumed to be mutually independent. Let $\pi\left(\mu, \sigma^{2}, r\right)$ represent the joint prior PDF, $\pi(\mu), \pi\left(\sigma^{2}\right), \pi(r)$ be the corresponding PDF of $\mu, \sigma, r$, respectively, then $\pi\left(\mu, \sigma^{2}, r\right)=\pi(\mu) \cdot \pi\left(\sigma^{2}\right) \cdot \pi(r)$.

Suppose that $\mathbf{X}=\left[X_{1}\left(t_{1}\right), X_{2}\left(t_{2}\right), \cdots, X_{n+1}\left(t_{n+1}\right)\right]$ is the real-time degradation data of an individual under normal stress level and $L\left(\Delta \mathbf{X} \mid \mu, \sigma^{2}, r\right)$ is a likelihood function, then the joint posterior PDF $\pi\left(\mu, \sigma^{2}, r \mid \Delta \mathbf{X}\right)$ can be deduced according to the Bayesian theory $[25,34]$.

$$
\begin{aligned}
& \pi\left(\mu, \sigma^{2}, r \mid \Delta \mathbf{X}\right) \\
& =\frac{L\left(\Delta \mathbf{X} \mid \mu, \sigma^{2}, r\right) \cdot \pi\left(\mu, \sigma^{2}, r\right)}{\int_{-\infty}^{+\infty} \int_{0}^{+\infty} \int_{-\infty}^{+\infty} L\left(\Delta \mathbf{X} \mid \mu, \sigma^{2}, r\right) \cdot \pi\left(\mu, \sigma^{2}, r\right) \mathrm{d} \mu \mathrm{d} \sigma^{2} \mathrm{~d} r}
\end{aligned}
$$

The marginal density functions of $\mu\left|\Delta \mathbf{X}, \sigma^{2}\right| \Delta \mathbf{X}, r \mid \Delta \mathbf{X}$ can be expressed as:

$$
\begin{aligned}
& \pi(\mu \mid \Delta \mathbf{X})=\int_{-\infty}^{+\infty} \int_{0}^{+\infty} \pi\left(\mu, \sigma^{2}, r \mid \Delta \mathbf{X}\right) \mathrm{d} \sigma^{2} \mathrm{~d} r \\
& \pi\left(\sigma^{2} \mid \Delta \mathbf{X}\right)=\int_{-\infty}^{+\infty} \int_{-\infty}^{+\infty} \pi\left(\mu, \sigma^{2}, r \mid \Delta \mathbf{X}\right) \mathrm{d} \mu \mathrm{d} r \\
& \pi(r \mid \Delta \mathbf{X})=\int_{0}^{+\infty} \int_{-\infty}^{+\infty} \pi\left(\mu, \sigma^{2}, r \mid \Delta \mathbf{X}\right) \mathrm{d} \mu \mathrm{d} \sigma^{2}
\end{aligned}
$$

Furthermore, the expectations of of $\mu\left|\Delta \mathbf{X}, \sigma^{2}\right| \Delta \mathbf{X}$ and $r \mid \Delta \mathbf{X}$ can be calculated as:

$$
\begin{gathered}
\mathrm{E}(\mu \mid \Delta \mathbf{X})=\int_{-\infty}^{+\infty} \mu \cdot \pi(\mu \mid \Delta \mathbf{X}) \mathrm{d} \mu \\
\mathrm{E}\left(\sigma^{2} \mid \Delta \mathbf{X}\right)=\int_{0}^{+\infty} \sigma^{2} \pi\left(\sigma^{2} \mid \Delta \mathbf{X}\right) \mathrm{d} \sigma^{2} \\
\mathrm{E}(r \mid \Delta \mathbf{X})=\int_{-\infty}^{+\infty} r \cdot \pi(r \mid \Delta \mathbf{X}) \mathrm{d} r
\end{gathered}
$$

Generally, it is difficult to evaluate $\mathrm{E}(\mu \mid \Delta \mathbf{X}), \mathrm{E}\left(\sigma^{2} \mid \Delta \mathbf{X}\right)$ and $\mathrm{E}(r \mid \Delta \mathbf{X})$ through direct mathematical calculation. One alternative method is using Markov Chain Monte Carlo (MCMC) simulation with Gibbs sampling $[16,20]$, we implemented the method in WinBUGS.

Replace $\mu, \sigma, \Lambda$ with $\mathrm{E}(\mu \mid \Delta \mathbf{X}), \mathrm{E}\left(\sigma^{2} \mid \Delta \mathbf{X}\right)$ and $\mathrm{E}(r \mid \Delta \mathbf{X})$ in Eq. (4) and Eq. (5), the posterior PDF of $R L$ and the posterior expectation of $R L$ can be obtained. There will be more field degradation data available as the individual product works over time. Once new degradation data is available, $\mathrm{E}(\mu \mid \Delta \mathbf{X}), \mathrm{E}\left(\sigma^{2} \mid \Delta \mathbf{X}\right)$ and $\mathrm{E}(r \mid \Delta \mathbf{X})$ are immediately updated. So the $R L$ of an individual can be real-time predicted.

\section{Evaluate the prior distributions of random param- eters}

Before predicting $R L$ using Bayesian method, the joint prior PDF $\pi\left(\mu, \sigma^{2}, r\right)$ need be evaluated from historical accelerated degradation data. In this section, we discussed the method of evaluating

$\pi\left(\mu, \sigma^{2}, r\right)$ from historical accelerated degradation data. Firstly, a Wiener process with 3 random parameters were used to model accelerated degradation data. Then, the acceleration factor constant principle was introduced to deduce the corresponding expression of acceleration factor for a Wiener process, and the parameter estimates were converted from accelerated stress levels to normal stress level through acceleration factors. Lastly, the Anderson-Darling goodnessof-fit method was utilized to select the proper distribution types for 3 random parameters.

\subsection{Estimate parameters from accelerated degradation data}

A constant stress accelerated degradation test was conducted to obtain the lifetime information of the population for a kind of highly reliable product. Suppose that $S_{0}$ denotes the normal stress level, $S_{k}$ denotes the $k$ th accelerated stress level, $X_{i j k}$ denotes the $i$ th degradation data of the $j$ th product under $S_{k}, t_{i j k}$ represents the corresponding observing time, $\Delta X_{i j k}=X_{i j k}-X_{(i-1) j k}$ represents the degradation data increment, and $\Lambda\left(t_{i j k}\right)=t_{i j k}^{\Lambda}$ represents the time increment, where $i=1,2, \cdots, n_{1} ; j=1,2, \cdots, n_{2} ; k=1,2, \cdots, n_{3}$. According to the Wiener process features, $\Delta X_{i j k}$ follows a Normal distribution as:

$$
\Delta X_{i j k} \sim \mathrm{N}\left(\mu_{j k} \Delta \Lambda\left(t_{i j k}\right), \sigma_{j k}^{2} \Delta \Lambda\left(t_{i j k}\right)\right)
$$

To obtain maximum likelihood estimates (MLEs) $\hat{\mu}_{j k}, \hat{\sigma}_{j k}^{2}, \hat{r}_{j k}$ for each product, the likelihood function can be established as:

$$
\begin{aligned}
& L\left(\mu_{j k}, \sigma_{j k}^{2}, r_{j k}\right) \\
& =\prod_{i=1}^{n_{1}} \frac{1}{\sqrt{2 \pi \sigma_{j k}^{2}\left(t_{i j k}^{r_{j k}}-t_{(i-1) j k}^{r_{j k}}\right)}} \exp \left[-\frac{\left(\Delta X_{i j k}-\mu_{j k}\left(t^{r_{j j k}}-t_{(i-1) j k}^{r_{j k}}\right)\right)^{2}}{2 \sigma_{j k}^{2}\left(t_{i j k}^{r_{j k}}-t_{(i-1) j k}^{r_{j k}}\right)}\right]
\end{aligned}
$$

\subsection{Convert parameter estimates from accelerated stress levels to normal stress level}

Suppose $F_{k}\left(t_{k}\right), F_{0}\left(t_{0}\right)$ represents the accumulative distribution function (CDF) under $S_{k}, S_{0}$, respectively, if $F_{k}\left(t_{k}\right)=F_{0}\left(t_{0}\right)$, then the acceleration factor of $S_{k}$ relative to $S_{0}$ can be defined as:

$$
A F_{k, 0}=t_{0} / t_{k}
$$

In practice, Eq. (15) is rarely applied to evaluate $A F_{k, 0}$ since $t_{0}$ and $t_{k}$ are difficult to accurately obtained. For a Wiener process, a widely adopted assumption is that $\mu$ should change with accelerated stress level varying while $\sigma$ should be invariable, see Padgett and Tomlinson [17], Park and Padgett [18], Liao and Tseng [11], Lim and 
Yum [14], et al. Based on the above assumption, the expression of $A F_{k, 0}$ can be expressed as $A F_{k, 0}=\mu_{k} / \mu_{0}$. However, there are different assumption that both $\mu$ and $\sigma$ will change with accelerated stress level varying, see Whitmore and Schenkelberg[31], Liao and Elsayed[12]. Thus, the expression of acceleration factor for a Wiener process needs further research. In this paper, we applied the acceleration factor constant principle to deduce the expression of acceleration factor for a Wiener process.

Zhou et al [35] first pointed out the acceleration factor constant principle that $A F_{k, 0}$ should be a constant which does not change with time $t_{0}, t_{k}$ and depends only on $S_{k}, S_{0}$ under an effective accelerated test. Moreover, to guarantee that $A F_{k, 0}$ is a constant, the failure mechanism of products must remain consistent under $S_{k}, S_{0}$. According to the accelerated factor constant principle, for any $t_{0}, t_{k}>0$, the following expression is always identical:

$$
F_{k}\left(t_{k}\right)=F_{0}\left(A F_{k, 0} t_{k}\right)
$$

From Eq. (16), the following identical equation can be deduced:

$$
f_{k}\left(t_{k}\right)=A F_{k, 0} \cdot f_{0}\left(t_{0}\right) .
$$

The deducing process was illustrated as:

$$
A F_{k, 0}=\mu_{k} / \mu_{0}=\sigma_{k}^{2} / \sigma_{0}^{2}
$$

Eq. (20) indicates that both $\mu$ and $\sigma$ should change with accelerated stress level varying. When we specify $\Lambda(t)=t^{r}$, the following equation can be deduced:

$$
A F_{k, 0}=\left(\mu_{k} / \mu_{0}\right)^{1 / r}=\left(\sigma_{k}^{2} / \sigma_{0}^{2}\right)^{1 / r}, r_{k}=r_{0}=r
$$

Eq. (21) indicates that both $\mu$ and $\sigma$ should change with accelerated stress level varying while $r$ should remain invariable. The mathematical relationships between $\mu, \sigma$ and accelerated stresses can be modeled by reaction rate models [15]. Assume that temperature $T$ is a stress variable and the Arrhenius relationship is correspondingly selected as the reaction rate model. According to Eq. (21), $\mu, \sigma^{2}$ and $r$ can be expressed as:

$$
\mu_{k}=\exp \left(\lambda_{1}-\lambda_{2} / T_{k}\right), \sigma_{k}^{2}=\exp \left(\lambda_{3}-\lambda_{2} / T_{k}\right), r_{k}=\lambda_{4}
$$

where $\lambda_{1}, \lambda_{2}, \lambda_{3}, \lambda_{4}$ are coefficients.

To obtain the MLEs of $\lambda_{1}, \lambda_{2}, \lambda_{3}, \lambda_{4}$, a likelihood function that incorporates all the accelerated degradation data was constructed:

$$
L\left(\lambda_{1}, \lambda_{2}, \lambda_{3}, \lambda_{4}\right)=\prod_{i=1}^{n_{1}} \prod_{j=1}^{n_{2}} \prod_{k=1}^{n_{3}} \frac{1}{\sqrt{2 \pi \exp \left(\lambda_{3}-\lambda_{2} / T_{k}\right)\left(t_{i j k}^{\lambda_{4}}-t_{(i-1) j k}^{\lambda_{4}}\right)}} \exp \left[-\frac{\left(\Delta x_{i j k}-\exp \left(\lambda_{1}-\lambda_{2} / T_{k}\right)\left(t_{i j k}^{\lambda_{4}}-t_{(i-1) j k}^{\lambda_{4}}\right)\right)^{2}}{2 \exp \left(\lambda_{3}-\lambda_{2} / T_{k}\right)\left(t_{i j k}^{\lambda_{4}}-t_{(i-1) j k}^{\lambda_{4}}\right)}\right]
$$

$$
\begin{aligned}
f_{k}\left(t_{k}\right) & =\frac{\mathrm{d} F_{k}\left(t_{k}\right)}{\mathrm{d} t_{k}}=A F_{k, 0} \frac{\mathrm{d} F_{0}\left(A F_{k, 0} \cdot t_{k}\right)}{\mathrm{d}\left(A F_{k, 0} \cdot t_{k}\right)} \\
& =A F_{k, 0} \frac{\mathrm{d} F_{0}\left(t_{0}\right)}{\mathrm{d}\left(t_{0}\right)}=A F_{k, 0} \cdot f_{0}\left(t_{0}\right)
\end{aligned}
$$

Substitute Eq. (3) into Eq. (17), and specify $\Lambda(t)=t$, then:

$$
\begin{aligned}
& A F_{k, 0}=\frac{f_{k}\left(t_{k}\right)}{f_{0}\left(t_{0}\right)}=\frac{\sigma_{0} A F_{k, 0}^{3 / 2}}{\sigma_{k}} \exp \left[\left(\frac{l \cdot \mu_{0}}{\sigma_{0}^{2}}-\frac{l \cdot \mu_{k}}{\sigma_{k}^{2}}\right)\right. \\
& \left.+\frac{1}{t_{k}}\left(\frac{l^{2}}{2 \sigma_{0}^{2} A F_{k, 0}}-\frac{l^{2}}{2 \sigma_{k}^{2}}\right)+t_{k}\left(\frac{\mu_{0}^{2} A F_{k, 0}}{2 \sigma_{0}^{2}}-\frac{\mu_{k}^{2}}{2 \sigma_{k}^{2}}\right)\right]
\end{aligned}
$$

To ensure $A F_{k, 0}$ is a constant which does not change with $t_{k}$, the following relationships must be satisfied:

$$
\left\{\begin{array}{l}
\frac{l^{2}}{2 \sigma_{0}^{2} A F_{k, 0}}-\frac{l^{2}}{2 \sigma_{k}^{2}}=0 \\
\frac{\mu_{0}^{2} A F_{k, 0}}{2 \sigma_{0}^{2}}-\frac{\mu_{k}^{2}}{2 \sigma_{k}^{2}}=0
\end{array}\right.
$$

With $\hat{\lambda}_{2}$ and $\hat{\lambda}_{2}, A F_{k, 0}$ was evaluated by:

$$
A F_{k, 0}=\exp \left(\hat{\lambda}_{4} \cdot \hat{\lambda}_{2}\left(1 / T_{0}-1 / T_{k}\right)\right)
$$

To simply the computation, $\left(A F_{k, 0}\right)^{\hat{\lambda}_{4}}$ was represented by $Z_{k, 0}$. Thus, the $\hat{\mu}_{j k}, \hat{\sigma}_{j k}^{2}, \hat{r}_{j k}^{2}$ under $T_{k}$ can be transformed into the corresponding values under $T_{0}$ by:

$$
\hat{\mu}_{j(k 0)}=\hat{\mu}_{j k} / Z_{k, 0}, \hat{\sigma}_{j(k 0)}^{2}=\sigma_{j k}^{2} / Z_{k, 0}, r_{j(k 0)}=r_{j k}
$$

For the denotation convenience, $\hat{\mu}_{j(k 0)}, \hat{\sigma}_{j(k 0)}^{2}$ and $\hat{r}_{j(k 0)}$ were replaced with $\hat{\mu}_{m}, \hat{\sigma}_{m}^{2}$ and $\hat{r}_{m}$, respectively, where $m=1,2, \cdots, M$ and $M$ denotes the total number of products under the accelerated test.

So the following equation can be deduced: 


\subsection{Select the best fitting distribution types and estimate hyper parameters}

We utilized the Anderson-Darling goodness-of-fit test to select the best fitting distribution types for $\hat{\mu}_{m}, \hat{\sigma}_{m}^{2}$ and $\hat{r}_{m}$. Since the Exponential, Normal, Lognormal, Weibull and Gamma distribution have good statistical characteristics and can cover the majority of parameter distribution, they were selected to be candidates for the best fitting distribution type. The one with the smallest $A D$ is considered to be the best fitting distribution type [24]. In addition, the Anderson-Darling statistic can also be used for hypothesis test. The null hypothesis is defined as H0: data follow the specified distribution type. The significance level is specified as 0.05 , if the $p$ value of Anderson-Darling is greater than 0.05 , the null hypothesis is accepted.

Suppose that $\hat{\mu}_{m} \sim \operatorname{Wbl}(\eta, \delta), \hat{\sigma}_{m}^{2} \sim \mathrm{Ga}(\alpha, \beta)$ and $\hat{r}_{m} \sim \mathrm{N}(a, b)$, where $\operatorname{Wbl}(\cdot)$ denotes a Weibull distribution and $\eta, \delta$ is the scale parameter and shape parameter, $\mathrm{Ga}(\cdot)$ denotes a Gamma distribution and $\alpha, \beta$ is the shape parameter and scale parameter, $\mathrm{N}(\cdot)$ denotes a Normal distribution and $a, b$ is the mean and variance. In order to estimate the hyper parameters, the following likelihood functions can be established:

$$
\begin{aligned}
& L\left(\hat{\mu}_{m} ; \eta, \delta\right)=\prod_{m=1}^{M} \delta \cdot \eta^{-\delta}\left(\hat{\mu}_{m}\right)^{\delta-1} \exp \left[-\left(\frac{\hat{\mu}_{m}}{\eta}\right)^{\delta}\right] \\
& L\left(\hat{\sigma}_{m}^{2} ; \alpha, \beta\right)=\prod_{m=1}^{M} \frac{\beta^{\alpha}}{\Gamma(\alpha)}\left(\hat{\sigma}_{m}^{2}\right)^{\alpha-1} \exp \left(-\beta \hat{\sigma}_{m}^{2}\right) \\
& L\left(\hat{r}_{m} ; a, b\right)=\prod_{m=1}^{M} \frac{1}{\sqrt{2 \pi \cdot b}} \exp \left(-\frac{\left(\hat{r}_{m}-a\right)^{2}}{2 \cdot b}\right)
\end{aligned}
$$

The prior distributions of random parameters $\mu, \sigma^{2}, r$ can be obtained as $\mu \sim \operatorname{Wbl}(\hat{\eta}, \hat{\delta}), \sigma^{2} \sim \operatorname{Ga}(\hat{\alpha}, \hat{\beta}), r \sim \mathrm{N}(\hat{a}, \hat{b})$.

\section{Validation test}

A simulation test was developed to validate the conversion method illustrated in section 3.2. The simulated degradation increment $\Delta x_{i 0}, \Delta \Lambda\left(t_{i 0}\right)$ under $S_{0}$ was generated from a conditional Wiener process[27,28], that is:

$$
\begin{aligned}
& \omega_{0} \sim \mathrm{Ga}(a, b), \quad \mu_{0} \mid \omega_{0} \sim \mathrm{N}\left(c, d / \omega_{0}\right) \\
& \Delta x_{i 0} \mid\left(\mu_{0}, \omega_{0}\right) \sim \mathrm{N}\left(\mu_{0} \Delta \Lambda\left(t_{i 0}\right), \omega_{0}^{-1} \Delta \Lambda\left(t_{i 0}\right)\right)
\end{aligned}
$$

where $\omega_{0}=\sigma_{0}^{-2}$ and $\Lambda(t)=t^{r}$. The parameters of the above model were specified as $(a, b, c, d)=(4,2,3,1) ; i=1,2, \cdots, 10 ; h=1,2, \cdots, 5$; $t_{i 0}=10,20, \cdots, 100 ; \quad \Lambda\left(t_{i 0}\right)=t_{i 0}^{r} ; \quad r=0.5,1,2$. The validation steps were described as the following. First, the estimates $\hat{\mu}_{0}, \hat{\sigma}_{0}^{2}, \hat{r}_{0}$ were obtained from $\Delta x_{i 0}, \Delta \Lambda\left(t_{i 0}\right)$. Then, specify the acceleration factor $A F_{k, 0}$ to be $0.4,4$, respectively, and calculate the converted degradation data $\Delta x_{i k}, \Delta \Lambda\left(t_{i k}\right)$ under $S_{k}$, where $x_{i k}=x_{i 0}, t_{i k}=t_{i 0} / A F_{k, 0}$ . Next, the estimates $\hat{\mu}_{k}, \hat{\sigma}_{k}^{2}, \hat{r}_{k}$ were obtained from $\Delta x_{i k}, \Delta \Lambda\left(t_{i k}\right)$. Last, $\hat{\mu}_{k} / \hat{\mu}_{0}, \hat{\sigma}_{k}^{2} / \hat{\sigma}_{0}^{2}$ and $\hat{r}_{k} / \hat{r}_{0}$ were computed. Table 1 shows that $\hat{r}_{k} / \hat{r}_{0}$ is nearly equal to 1 and both $\hat{\mu}_{k} / \hat{\mu}_{0}$ and $\hat{\sigma}_{k}^{2} / \hat{\sigma}_{0}^{2}$ are nearly equal to $\left(A F_{k, h}\right)^{r}$, so the result is consistent with Eq. (21).

Table 1. The results of simulation test

\begin{tabular}{||c|c|c|c|c|c|c||}
\hline \multirow{2}{*}{$r$} & \multicolumn{3}{|c|}{$A F_{k, h}=0.4$} & \multicolumn{3}{c||}{$A F_{k, h}=4$} \\
\cline { 2 - 7 } & $\hat{\mu}_{k}$ & $\frac{\hat{\sigma}_{k}^{2}}{\hat{\mu}_{0}^{2}}$ & $\frac{\hat{r}_{k}}{\hat{\sigma}_{0}}$ & $\frac{\hat{\mu}_{k}}{\hat{\mu}_{0}}$ & $\frac{\hat{\sigma}_{k}^{2}}{\hat{\sigma}_{0}^{2}}$ & $\frac{\hat{r}_{k}}{\hat{r}_{0}}$ \\
\hline 0.5 & 0.6325 & 0.6324 & 1.0002 & 2.0000 & 2.0002 & 1.0001 \\
\hline 1 & 0.4000 & 0.4000 & 1.0000 & 4.0001 & 4.0001 & 1.0000 \\
\hline 2 & 0.1600 & 0.1600 & 0.9999 & 15.9999 & 16.0002 & 1.0000 \\
\hline
\end{tabular}

\section{Numerical case}

\subsection{Modeling degradation data}

The historical accelerated degradation data of self-regulating heating cable[31] was listed in Table 2. Because the type of heating cable experienced a cure process at the beginning of the degradation test, only the degradation data after the cure process were considered. There were 15 products that were averagely allocated to 3 accelerated temperature levels under a constant-stress ADT. It was assumed that the normal temperature level was $T_{0}=448.15 \mathrm{~K}$. Degradation was measured as the natural logarithm of resistance, and the failure threshold $l$ was specified as $l=\ln (2)$.

However, there was no field degradation data available under $T_{0}$. We simulated the field degradation data which are listed in Table 3.

\subsection{Determining prior distribution}

Eq. (14) was used to obtain the MLEs of parameters for each product, and the estimates were listed in Table 4. For a Wiener degradation process, the independent degradation increments $\Delta x_{i j k}$ of each product follows a Normal distribution, written as $\Delta x_{i j k} \sim \mathrm{N}\left(\hat{\mu}_{j k} \Delta \hat{\Lambda}_{j k}\left(t_{i j k}\right), \hat{\sigma}_{j k}^{2} \Delta \hat{\Lambda}_{j k}\left(t_{i j k}\right)\right)$, where $\hat{\mu}_{j k}, \hat{\sigma}_{j k}^{2}, \hat{r}_{j k}$ are the estimates of the $j$ th product under the $k$ th accelerated temperature level $T_{k}$. The above Normal distribution can be converted to the following standard Normal distribution:

$\left(\Delta x_{i j k}-\hat{\mu}_{j k} \Delta \widehat{\Lambda}_{j k}\left(t_{i j k}\right)\right) / \sqrt{\hat{\sigma}_{j k}^{2} \Delta \widehat{\Lambda}_{j k}\left(t_{i j k}\right)} \sim \mathrm{N}(0,1)$. If the above relationship holds, the null hypothesis that the degradation process of the $j$ th product under $T_{k}$ obeys a Wiener process is accepted. An Anderson-Darling test with significance level $\alpha=0.05$ validates that the degradation processes of all products obey Wiener processes. 
Table 2. Historical accelerated degradation data of heating cables

\begin{tabular}{|c|c|c|c|c|c|}
\hline \multirow{2}{*}{$\begin{array}{c}\text { Measured } \\
\text { time } \\
\left(\times 10^{3} \mathrm{~h}\right)\end{array}$} & \multicolumn{5}{|c|}{ Item } \\
\hline & 1 & 2 & 3 & 4 & 5 \\
\hline \multicolumn{6}{|c|}{ (a) $T_{1}=473.15 \mathrm{~K}$} \\
\hline 0.496 & -0.120682 & -0.118779 & -0.123600 & -0.126501 & -0.124359 \\
\hline 0.688 & -0.112403 & -0.109853 & -0.115186 & -0.118941 & -0.111966 \\
\hline 0.856 & -0.103608 & -0.101593 & -0.105657 & -0.110288 & -0.107869 \\
\hline 1.024 & -0.096047 & -0.094567 & -0.098569 & -0.103419 & -0.100304 \\
\hline 1.192 & -0.085673 & -0.084698 & -0.088613 & -0.095465 & -0.085916 \\
\hline 1.360 & -0.077677 & -0.076070 & -0.079332 & -0.084769 & -0.077947 \\
\hline 2.008 & -0.045218 & -0.040623 & -0.045835 & -0.052268 & -0.045597 \\
\hline 2.992 & 0.000526 & 0.004237 & 0.000533 & -0.008265 & 0.000524 \\
\hline 4.456 & 0.059261 & 0.063742 & 0.061032 & 0.051139 & 0.059544 \\
\hline 5.608 & 0.093394 & 0.095117 & 0.093612 & 0.082414 & 0.084912 \\
\hline \multicolumn{6}{|c|}{ (b) $T_{2}=513.15 \mathrm{~K}$} \\
\hline 0.160 & -0.005152 & -0.019888 & -0.045961 & -0.023188 & -0.044267 \\
\hline 0.328 & 0.056930 & 0.046278 & 0.015198 & 0.040737 & 0.018173 \\
\hline 0.496 & 0.112631 & 0.101628 & 0.067119 & 0.095504 & 0.072214 \\
\hline 0.688 & 0.173202 & 0.162705 & 0.128670 & 0.156129 & 0.131555 \\
\hline 0.856 & 0.214266 & 0.202604 & 0.168271 & 0.196349 & 0.171394 \\
\hline 1.024 & 0.272668 & 0.257563 & 0.221611 & 0.250900 & 0.225281 \\
\hline 1.192 & 0.311422 & 0.297875 & 0.260910 & 0.291937 & 0.266314 \\
\hline 1.360 & 0.351988 & 0.338902 & 0.302126 & 0.332887 & 0.306105 \\
\hline 2.008 & 0.489847 & 0.461855 & 0.440738 & 0.473130 & 0.443941 \\
\hline 2.992 & 0.656780 & 0.629991 & 0.606275 & 0.638651 & 0.611724 \\
\hline 4.456 & 0.851985 & 0.798431 & 0.834114 & 0.798457 & - \\
\hline \multicolumn{6}{|c|}{ (c) $T_{3}=533.15 \mathrm{~K}$} \\
\hline 0.160 & 0.123360 & 0.127605 & 0.120759 & 0.105206 & 0.120115 \\
\hline 0.328 & 0.251084 & 0.254944 & 0.247156 & 0.232389 & 0.247949 \\
\hline 0.496 & 0.393107 & 0.394496 & 0.391516 & 0.375789 & 0.388406 \\
\hline 0.688 & 0.517137 & 0.518485 & 0.513872 & 0.500556 & 0.511850 \\
\hline 0.856 & 0.598797 & 0.599265 & 0.595704 & 0.583362 & 0.595220 \\
\hline 1.024 & 0.693925 & 0.694445 & 0.688930 & 0.679117 & 0.690324 \\
\hline 1.192 & 0.774347 & 0.774428 & 0.770313 & 0.758314 & 0.770782 \\
\hline
\end{tabular}

* A period denotes a missing value.

Table 3. The simulated field degradation data for an individual heating cable at $T_{0}$

\begin{tabular}{||c|c|c|c|c|c||}
\hline Time $/ \mathrm{h}$ & 1000 & 2000 & 3000 & 4000 & 5000 \\
\hline Degradation & -0.2209 & -0.1984 & -0.1815 & -0.1651 & -0.1555 \\
\hline Time /h & 6000 & 7000 & 8000 & 9000 & \\
\hline Degradation & -0.1443 & -0.1323 & -0.1231 & -0.1128 & \\
\hline
\end{tabular}

With Eq. (23), we obtained the MLEs of coefficients as $\hat{\lambda}_{1}=16.950, \hat{\lambda}_{2}=9158.226, \hat{\lambda}_{3}=10.317, \hat{\lambda}_{4}=0.612$. According to the Eq. (23), conversion coefficients were calculated as $Z_{1,0}=2.944$, $Z_{2,0}=13.311, Z_{3,0}=25.999$. Furthermore, we converted the MLEs
Table 4. MLEs of parameters for each product

\begin{tabular}{|c|c|c|c|c|c|}
\hline & \multicolumn{5}{|c|}{ Item } \\
\hline & 1 & 2 & 3 & 4 & 5 \\
\hline \multicolumn{6}{|c|}{ (a) $T_{1}$} \\
\hline$\widehat{\mu}$ & 0.067029 & 0.070533 & 0.070463 & 0.064605 & 0.083435 \\
\hline$\hat{\sigma}^{2}$ & 0.000026 & 0.000039 & 0.000035 & 0.000039 & 0.000120 \\
\hline$\hat{r}$ & 0.770668 & 0.74692 & 0.754380 & 0.776351 & 0.662973 \\
\hline \multicolumn{6}{|c|}{ (b) $T_{2}$} \\
\hline$\widehat{\mu}$ & 0.402341 & 0.425767 & 0.367615 & 0.427607 & 0.369066 \\
\hline$\hat{\sigma}^{2}$ & 0.000442 & 0.000523 & 0.000230 & 0.000753 & 0.000214 \\
\hline$\hat{r}$ & 0.602857 & 0.553023 & 0.662489 & 0.552906 & 0.665158 \\
\hline \multicolumn{6}{|c|}{ (c) $T_{3}$} \\
\hline$\hat{\mu}$ & 0.788653 & 0.781201 & 0.788428 & 0.791756 & 0.784433 \\
\hline$\hat{\sigma}^{2}$ & 0.00117 & 0.001096 & 0.001283 & 0.001255 & 0.001017 \\
\hline$\hat{r}$ & 0.661216 & 0.664650 & 0.659024 & 0.660437 & 0.666665 \\
\hline
\end{tabular}

of parameters under $T_{k}$ to the corresponding values $\hat{\mu}_{m}, \hat{\sigma}_{m}^{2}, \hat{r}_{m}$ under $T_{0}$, respectively, as listed in Table 5 .

Anderson-Darling statistic was applied to determining the best fitting distribution. Table 6 shows the values of $A D$. Since $\hat{\sigma}_{m}^{2}$ should be always large than zero, the Normal distribution is excluded. From Table 6, it was concluded that the Weibull distribution was the best fitting distribution type for both $\hat{\mu}_{m}$ and $\hat{\sigma}_{m}^{2}$, and the Normal distribu-

Table 5. The converted values $\hat{\mu}_{m}, \hat{\sigma}_{m}^{2}, \hat{r}_{m}$

\begin{tabular}{|c|c|c|c|c|c|}
\hline & \multicolumn{5}{|c|}{ Item } \\
\hline & 1 & 2 & 3 & 4 & 5 \\
\hline \multicolumn{6}{|c|}{ (a) $T_{1} \rightarrow T_{0}$} \\
\hline$\hat{\mu}_{m}$ & 2.277E-2 & $2.396 \mathrm{E}-2$ & 2.393E-2 & 2.194E-2 & $2.834 \mathrm{E}-2$ \\
\hline$\hat{\sigma}_{m}^{2}$ & 8.832E-6 & $1.325 \mathrm{E}-5$ & $1.189 \mathrm{E}-5$ & $1.325 \mathrm{E}-5$ & $4.076 \mathrm{E}-5$ \\
\hline$\hat{r}_{m}$ & 0.771 & 0.747 & 0.754 & 0.776 & 0.663 \\
\hline \multicolumn{6}{|c|}{ (b) $T_{2} \rightarrow T_{0}$} \\
\hline$\hat{\mu}_{m}$ & $3.023 \mathrm{E}-2$ & 3.199E-2 & $2.762 \mathrm{E}-2$ & $3.213 \mathrm{E}-2$ & $2.773 \mathrm{E}-2$ \\
\hline$\hat{\sigma}_{m}^{2}$ & $3.321 \mathrm{E}-5$ & $3.929 \mathrm{E}-5$ & $1.728 \mathrm{E}-5$ & 5.657E-5 & $1.608 \mathrm{E}-5$ \\
\hline$\hat{r}_{m}$ & 0.603 & 0.553 & 0.662 & 0.553 & 0.665 \\
\hline \multicolumn{6}{|c|}{ (c) $T_{3} \rightarrow T_{0}$} \\
\hline$\hat{\mu}_{m}$ & $3.033 \mathrm{E}-2$ & $3.005 \mathrm{E}-2$ & $3.033 \mathrm{E}-2$ & $3.045 \mathrm{E}-2$ & 3.017E-2 \\
\hline$\hat{\sigma}_{m}^{2}$ & $4.500 \mathrm{E}-5$ & $4.216 \mathrm{E}-5$ & $4.935 \mathrm{E}-5$ & 4.827E-5 & $3.912 \mathrm{E}-5$ \\
\hline$\hat{r}_{m}$ & 0.661 & 0.665 & 0.659 & 0.660 & 0.667 \\
\hline
\end{tabular}


Table 6. The values of $A D$

\begin{tabular}{||c|c|c|c|c|c||}
\hline \hline & Exponential & Normal & LogNorm & Gamma & Weibull \\
\hline$\hat{\mu}_{m}$ & 5.449 & 0.905 & 1.016 & 1.032 & 0.806 \\
\hline$\hat{\sigma}_{m}^{2}$ & 1.733 & -- & 0.985 & 0.980 & 0.952 \\
\hline$\hat{r}_{m}$ & 5.682 & 0.878 & 0.894 & 0.914 & 0.982 \\
\hline
\end{tabular}

Table 7. The posterior means of random parameters after the 5th field degradation data was got

\begin{tabular}{||c|c|c|c|c||}
\hline \hline Parameter & $\begin{array}{c}\text { Posterior } \\
\text { mean }\end{array}$ & $\begin{array}{c}\text { Standard } \\
\text { deviation }\end{array}$ & MC error & Samples \\
\hline$\mu$ & 0.02930 & 0.00299 & $2.86 \mathrm{E}-5$ & 9000 \\
\hline$\sigma^{2}$ & $4.149 \mathrm{E}-5$ & $1.568 \mathrm{E}-5$ & $1.59 \mathrm{E}-7$ & 9000 \\
\hline$r$ & 0.6124 & 0.0601 & $6.391 \mathrm{E}-4$ & 9000 \\
\hline
\end{tabular}

a) $\mu$

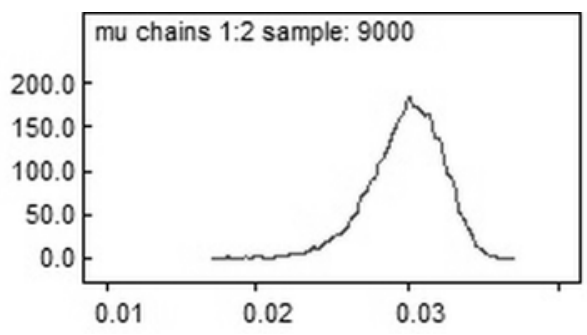

b) $\sigma^{2}$

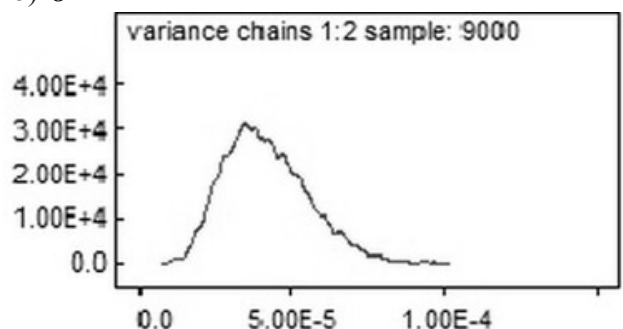

c) $r$

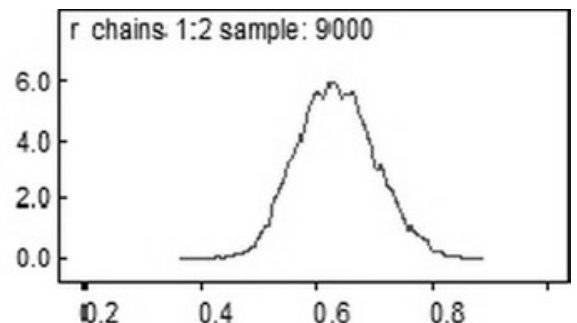

Fig. 1. The fitted posterior distributions of $\mu, \sigma^{2}, r$

a) $\mu$

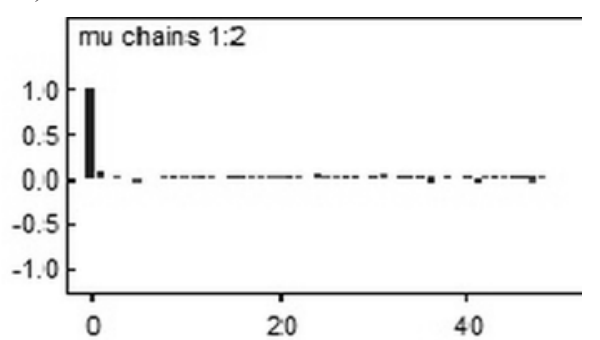

b) $\sigma^{2}$

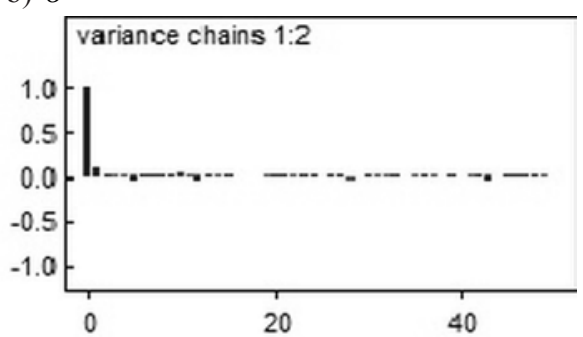

c) $r$

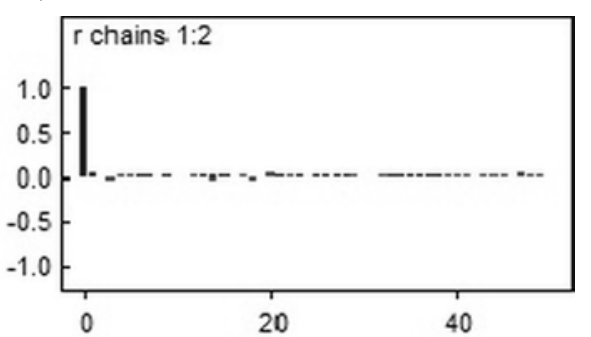

Fig. 2. The values of autocorrelation function in the iterative processes

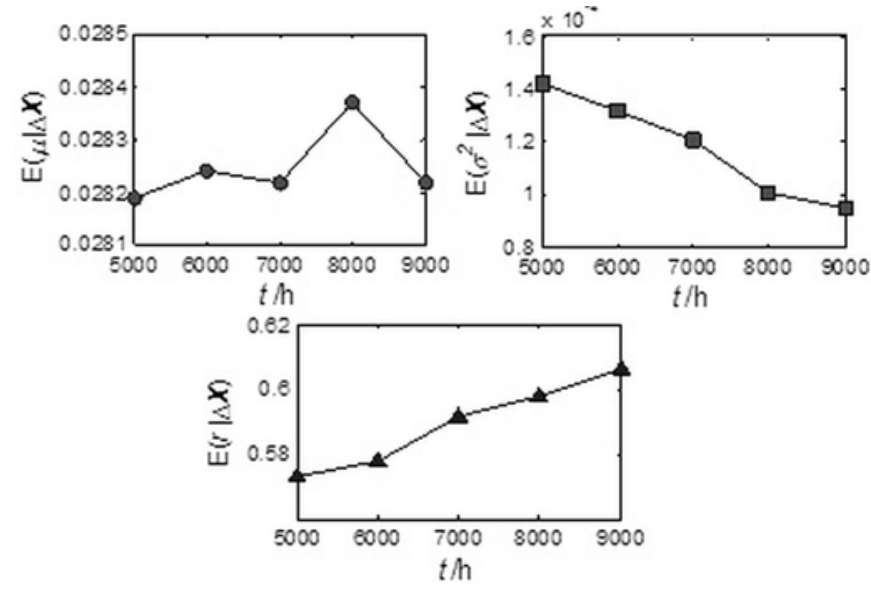

Fig. 3. The changing curves of the posterior means of random parameters

tion was the best fitting distribution type for $\hat{r}_{m}$. The MLEs of hyper parameters were obtained according to Eq. (26) and Eq. (27). So the prior distributions of 3 random parameters were evaluated from historical accelerated degradation data, they are $\mu \sim \mathrm{Wbl}(2.952 \mathrm{E}-2,11.464)$ , $\sigma^{2} \sim \operatorname{Wbl}(3.580 \mathrm{E}-5,2.150), r \sim \mathrm{N}(0.671,4.774 \mathrm{E}-3)$.

After the field degradation data was obtained, the MCMC method with Gibbs sampling was used to fit the posterior distributions of random parameters in WinBUGS software. After the 5th field degradation data was got, the fitted posterior distributions were shown in figure 1. From figure 2, it can be seen that all the iterative processes are convergent since the autocorrelation functions quickly tend to 0 . The

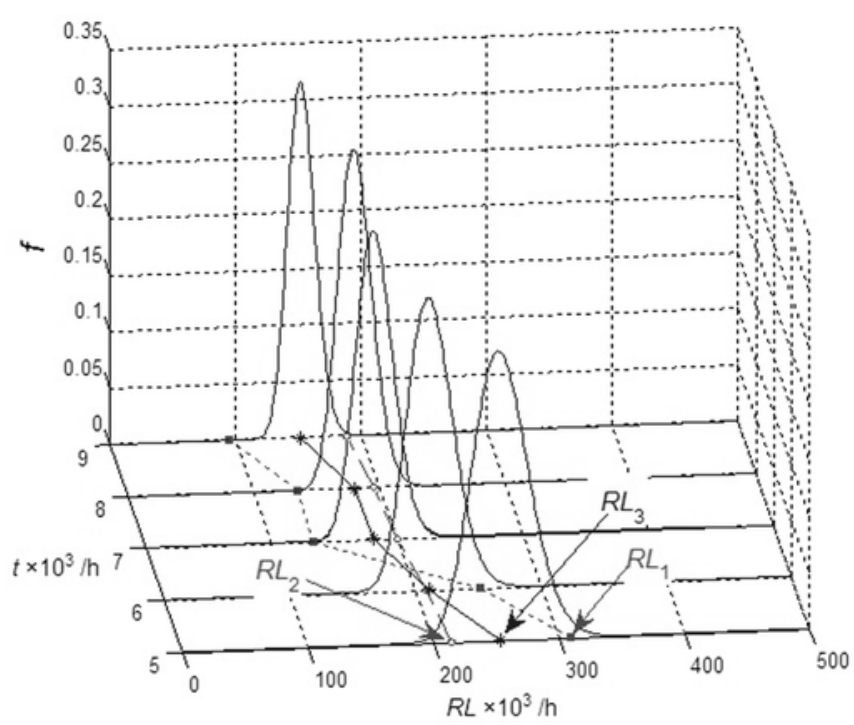

Fig. 4. The changing curves of $\overline{R L_{1}}, \overline{R L_{2}}, \overline{R L_{3}}$ and the PDF of $R L_{3}$

posterior means $\mathrm{E}(\mu \mid \Delta \mathbf{X}), \mathrm{E}\left(\sigma^{2} \mid \Delta \mathbf{X}\right)$ and $\mathrm{E}(r \mid \Delta \mathbf{X})$ were evaluated in WinBUGS, as listed in table 7. Furthermore, with new field degradation data was available, $\mathrm{E}(\mu \mid \Delta \mathbf{X}), \mathrm{E}\left(\sigma^{2} \mid \Delta \mathbf{X}\right)$ and $\mathrm{E}(r \mid \Delta \mathbf{X})$ were corresponding updated, and their changing curves were shown in Figure 3.

Let $\overline{R L_{1}}$ denote the predictions that were evaluated from only the field degradation data of an individual, $\overline{R L_{2}}$ denote the predic- 
Table 8. The predictions of residual life $\left(R L \times 10^{5} / h\right)$

\begin{tabular}{||c|c|c|c|c|c|}
\hline \multirow{3}{*}{} & \multicolumn{5}{|c|}{ Measuring time $/ \mathrm{h}$} \\
\cline { 2 - 6 } & 5000 & 6000 & 7000 & 8000 & 9000 \\
\hline$\overline{R L}_{1}$ & 3.089 & 2.513 & 1.332 & 1.341 & 0.939 \\
& {$[1.885,5.301]$} & {$[1.211,4.018]$} & {$[0.978,3.890]$} & {$[1.012,3.805]$} & {$[0.762,2.981]$} \\
\hline$\overline{R L}_{2}$ & 2.145 & 2.081 & 2.004 & 1.949 & 1.874 \\
& {$[1.421,2.876]$} & {$[1.450,2.772]$} & {$[1.498,2.624]$} & {$[1.519,2.468]$} & {$[1.466,2.303]$} \\
\hline$\overline{R L}_{3}$ & 2.536 & 2.116 & 1.816 & 1.802 & 1.518 \\
& {$[1.758,3.212]$} & {$[1.449,2.801]$} & {$[1.209,2.488]$} & {$[1.233,2.317]$} & {$[1.087,1.955]$} \\
\hline
\end{tabular}

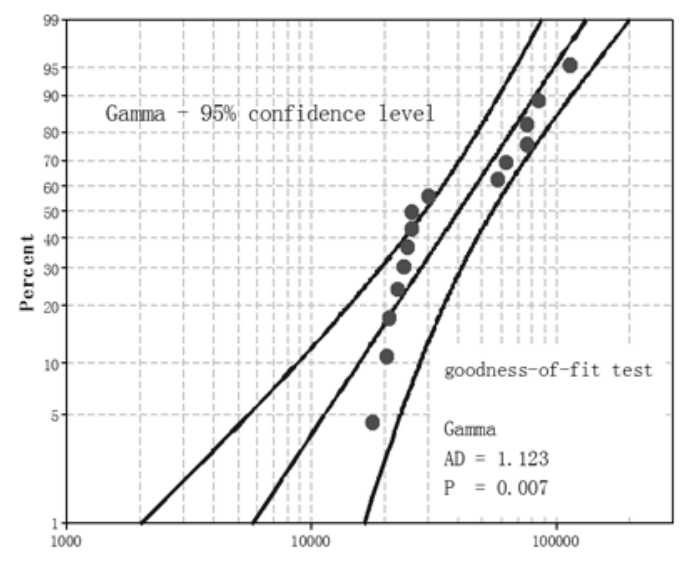

$\hat{\omega}_{m}$

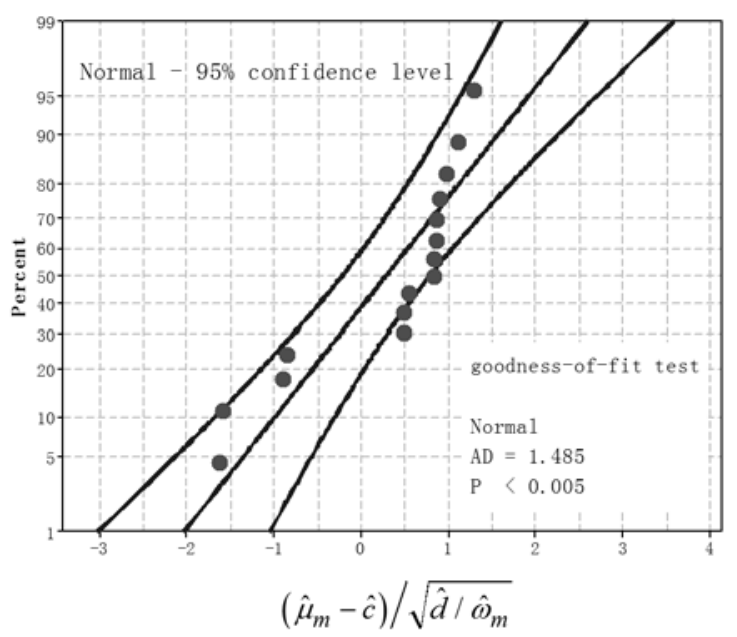

$\left(\hat{\mu}_{m}-\hat{c}\right) / \sqrt{\hat{d} / \hat{\omega}_{m}}$

pared with $\overline{R L}_{3}$, the curve of $\overline{R L}_{2}$ was more smooth and had smaller changes, because the prediction method for $\overline{R L}_{2}$ didn't consider the random effects of $r$. The estimates of $r$ obtained from the prior information was used to the prediction model of $\overline{R L}_{2}$. Thus, $\overline{R L}_{2}$ was more conservative and greatly influenced by the prior information. In contrast, the prediction method for $\overline{R L}_{3}$ took the random effects of 3 parameters into account, which let $\overline{R L}_{3}$ more sensitively reflect the variation of the field degradation data.

In addition, the prediction method for $\overline{R L}_{2}$ requires $\hat{\mu}_{z}$ and $\hat{\sigma}_{z}^{2}$ to follow the conjugate prior distributions as $\widehat{\omega}_{m}=\hat{\sigma}_{m}^{-2} \sim \operatorname{Ga}(\hat{a}, \hat{b})$,

$$
\hat{\mu}_{m} \mid \hat{\omega}_{m} \sim \mathrm{N}\left(\hat{c}, \hat{d} / \hat{\omega}_{m}\right),
$$

where $\hat{a}, \hat{b}, \hat{c}, \hat{d}$ are estimates of hyper parameters and $z=1,2, \cdots, 15$. The AndersonDarling statistic was used to validate the null hypothesis that both $\hat{\mu}_{m}$ and $\hat{\sigma}_{m}^{2}$ to follow the conjugate prior distributions.

tions that were evaluated by the Bayesian method with conjugate prior distributions of random parameters, $\overline{R L_{3}}$ denote the predictions that were evaluated by the method proposed in this paper, the residual life predictions and the confidence intervals of the predictions at several measuring time points were summarized in table 8 . The confidence intervals were obtained with $95 \%$ confidence level by Bootstrap sampling method. The prediction method for $\overline{R L_{2}}$ was detailed demonstrated in appendix. Figure 4 shows the changing curves of $\overline{R L_{1}}, \overline{R L_{2}}$, $\overline{R L_{3}}$ and the PDF of $R L_{3}$.

\subsection{Analysis and Conclusion}

In table 7 , the confidence intervals of $\overline{R L}_{2}$ and $\overline{R L}_{3}$ at each measuring point are obviously smaller than those of $\overline{R L}_{1}$. It is concluded that the prediction method taking accelerated degradation data as prior information improves the prediction precision of the residual life.

As more field degradation data was available, all the confidence intervals of $\overline{R L}_{1}, \overline{R L}_{2}, \overline{R L}_{3}$ became smaller. It suggests that the prediction precision was gradually improved, and the width of the PDF curve in figure 4 became narrower over time also supports the conclusion.

Compared with $\overline{R L}_{2}$ and $\overline{R L}_{3}$, the curve of $\overline{R L}_{1}$ was not smooth and presented comparatively big changes. The reason is that the field degradation data was short and had a nonlinear change. Thus, newly obtained degradation data may significantly changes the former estimates of the parameters, which leaded to the poor regularity of residual life predictions. In comparison, the prediction methods for $\overline{R L}_{2}$ and $\overline{R L}_{3}$ reduced the impact of the abrupt change of the field degradation and improved the reliability of the prediction results. Com- $\hat{\mu}_{m} \mid \hat{\omega}_{m} \sim \mathrm{N}\left(\hat{c}, \hat{d} / \hat{\omega}_{m}\right)$ was converted to $\left(\hat{\mu}_{m}-\hat{c}\right) / \sqrt{\hat{d} / \hat{\omega}_{m}} \sim \mathrm{N}(0,1)$ according to the characteristics of Normal distribution. The significance level was specified as 0.5 , and the information of the goodnessof-fit test was shown in figure 5. The null hypothesis was rejected since the values of $p$ were less than 0.05 . It would cause the misspecification of distribution types of random parameters if the prediction method for $\overline{R L}_{2}$ was adopted in the case study. Therefore, it was appropriate and reliable to adopt the prediction method for $\overline{R L}_{3}$ in the case study.

\section{Conclusions}

In this paper, a residual life prediction method for degradation product based on Bayesian inference was proposed. A Wiener process with a time function was used to model degradation data.

Our proposed method made two potential novel contributions. a). Acceleration factor was introduced to transform the test data from accelerated stresses to normal use stress, so that accelerated degradation data can be considered as prior information. b). The non-conjugate prior distributions of random parameters were applied to Bayesian inference, which not only can consider the random effects of all the parameters but also can avoid the potential misspecifications of the parameter distributions when conjugate prior distributions were adopted.

Besides, there are several meaningful workings and conclusions about the study of the paper.

1) The residual life prediction method based on Bayesian inference that integrated the field degradation data and accelerated 
degradation data can improve the prediction accuracy and realize real-time updating for the residual life.

2) The acceleration factor constant principle was used to deduce the relationships that the parameters of the Wiener process with a time function should satisfy. It offered a feasible approach to constructing the acceleration models for the parameters of the Wiener process.

\section{Appendix}

With $\hat{\mu}_{m}, \hat{\omega}_{m}$ the prior estimates of hyper parameters $a, b, c, d$ can be obtained from:

$$
\begin{aligned}
L\left(\hat{\omega}_{m} ; a, b\right) & =\prod_{m=1}^{M} \frac{b^{a}}{\Gamma(a)} \hat{\omega}_{m}^{a-1} \exp \left(-b \hat{\omega}_{m}\right) \\
L\left(\hat{\mu}_{m} \mid \hat{\omega}_{m} ; c, d\right) & =\prod_{m=1}^{M} \frac{\hat{\omega}_{m}^{0.5}}{\sqrt{2 \pi d}} \exp \left(-\frac{\hat{\omega}_{m}\left(\hat{\mu}_{m}-c\right)^{2}}{2 d}\right)
\end{aligned}
$$

From the field degradation data $\mathbf{X}=\left[X_{1}\left(t_{1}\right), X_{2}\left(t_{2}\right), \cdots, X_{n+1}\left(t_{n+1}\right)\right]$, the posterior estimates of hyper parameters can be deduced according to the Bayesian formula:

$$
\pi(\mu, \omega \mid \Delta \mathbf{X})=\frac{L(\Delta \mathbf{X} \mid \mu, \omega) \cdot \pi(\mu, \omega)}{\int_{0}^{+\infty} \int_{-\infty}^{+\infty} L(\Delta \mathbf{X} \mid \mu, \omega) \cdot \pi(\mu, \omega) \mathrm{d} \mu \mathrm{d} \omega}
$$

where $L(\Delta \mathbf{X} \mid \mu, \omega)$ is a likelihood function $\pi(\mu, \omega)$ is the joint prior PDF of $\mu$ and $\omega$, denoted as $\pi(\mu, \omega)=\pi(\mu \mid \omega) \cdot \pi(\omega)$ and $\pi(\mu, \omega \mid \Delta \mathbf{X})$ is the joint posterior PDF.

Substitute:

$$
\begin{aligned}
& \pi(\mu, \omega) \\
& =\frac{\omega^{1 / 2}}{\sqrt{2 \pi \hat{d}}} \exp \left(\frac{-\omega(\mu-\hat{d})^{2}}{2 \hat{d}}\right) \cdot \frac{\hat{b}^{\hat{a}}}{\Gamma(\hat{a})} \omega^{\hat{a}-1} \exp (-\hat{b} \omega)
\end{aligned}
$$

and:

$$
\begin{aligned}
& L(\Delta \mathbf{X} \mid \mu, \omega) \\
& =\prod_{j=1}^{n} \frac{\omega^{1 / 2}}{\sqrt{2 \pi \Delta \Lambda\left(t_{j}\right)}} \exp \left(\frac{-\omega\left(\Delta X_{j}-\mu \cdot \Delta \Lambda\left(t_{j}\right)\right)^{2}}{2 \Delta \Lambda\left(t_{j}\right)}\right)
\end{aligned}
$$

into (A.3), then:

$$
\begin{aligned}
& \pi(\mu, \omega \mid \Delta \mathbf{X}) \\
& \propto L(\Delta \mathbf{X} \mid \mu, \omega) \cdot \pi(\mu, \omega) \\
& \propto \omega^{(n+1) / 2+\hat{a}-1} \exp \left\{-\frac{\omega}{2}\left(\mu^{2} \sum_{j=1}^{n} \Delta \Lambda\left(t_{j}\right)-2 \mu \sum_{j=1}^{n} \Delta X_{j}+\sum_{j=1}^{n} \frac{\Delta X_{j}^{2}}{\Delta \Lambda\left(t_{j}\right)}\right)-\frac{\omega}{2}\left(\frac{(\mu-\hat{c})^{2}}{\hat{d}}\right)-\hat{b} \omega\right\} \\
& \propto \omega^{n / 2+\hat{a}-1} \exp \left\{-\omega\left(\hat{b}+\frac{\hat{c}^{2}}{2 \hat{d}}-\frac{\left(\hat{d} \sum_{j=1}^{n} \Delta X_{j}+\hat{c}\right)^{2}}{2\left(\hat{d}^{2} \sum_{j=1}^{n} \Delta \Lambda\left(t_{j}\right)+\hat{d}\right)}+\sum_{j=1}^{n} \frac{\Delta X_{j}^{2}}{2 \Delta \Lambda\left(t_{j}\right)}\right)\right\} \omega^{1 / 2} \cdot \exp \left\{-\frac{\omega}{2} \frac{\left(\mu-\frac{\hat{d} \sum_{j=1}^{n} \Delta X_{j}+\hat{d}}{\hat{d} \sum_{j=1}^{n} \Delta \Lambda\left(t_{j}\right)+1}\right)^{2}}{\frac{\hat{d}}{\hat{d} \sum_{j=1}^{n} \Delta \Lambda\left(t_{j}\right)+1}}\right\}
\end{aligned}
$$
evaluated.
The form of $\Lambda(t)$ was specified as $\Lambda(t)=t^{\hat{r}}$, where $\hat{r}$ was estimated from the accelerated degradation data. Furthermore, the posterior means $\mathrm{E}(\mu \mid \Delta \mathbf{X}), \mathrm{E}(\omega \mid \Delta \mathbf{X})$ of $\mu, \omega$ were evaluated. Substitute $\mathrm{E}(\mu \mid \Delta \mathbf{X}), \mathrm{E}(\omega \mid \Delta \mathbf{X})$ and $\Lambda(t)=t^{\hat{r}}$ into Eq.(4) and (5), $\overline{R L}_{2}$ can be
3) The prediction method that adopts non-conjugate prior distributions can be applied to more cases, since it dose not require parameters to follow the specified distribution types. Moreover, the assumption that parameters are mutually independent facilitates the engineering application of the method.

The posterior estimates of hyper parameters can be obtained as:

$$
\begin{aligned}
& \hat{a} \mid \Delta \mathbf{X}=\frac{n}{2}+\hat{a}, \\
& \hat{b} \mid \Delta \mathbf{X}=\hat{b}+\frac{\hat{c}^{2}}{2 \hat{d}}-\frac{\left(\hat{d} \sum_{j=1}^{n} \Delta X_{j}+\hat{c}\right) \hat{c}^{2}}{2\left(\hat{d}^{2} \sum_{j=1}^{n} \Delta \Lambda\left(t_{j}\right)+\hat{d}\right)}+\sum_{j=1}^{n} \frac{\Delta X_{j}^{2}}{2 \Delta \Lambda\left(t_{j}\right)} \\
& \hat{c}\left|\Delta \mathbf{X}=\frac{\hat{d} \sum_{j=1}^{n} \Delta X_{j}+\hat{c}}{\hat{d} \sum_{j=1}^{n} \Delta \Lambda\left(t_{j}\right)+1}, \hat{d}\right| \Delta \mathbf{X}=\frac{\hat{d}}{\hat{d} \sum_{j=1}^{n} \Delta \Lambda\left(t_{j}\right)+1}
\end{aligned}
$$




\section{References}

1 Baraldi P, Mangili F, Zio E. A prognostics approach to nuclear component degradation modeling based on Gaussian process regression. Progress in Nuclear Energy 2015; 78: 141-154, http://dx.doi.org/10.1016/j.pnucene.2014.08.006.

2. Chakraborty S, Gebraeel N, Lawley M, et al. Residual-life estimation for components with non-symmetric priors. IIE Transactions 2009; 41(4): 372-387, http://dx.doi.org/10.1080/07408170802369409.

3. Chiachio J, Chiachio M, Saxena A, et al. Bayesian model selection and parameter estimation for fatigue damage progression models in composites. International Journal of Fatigue 2015; 70: 361-373, http://dx.doi.org/10.1016/j.ijfatigue.2014.08.003.

4. Huang Z Y, Xu Z G, Wang W H, et al. Remaining useful life prediction for a nonlinear heterogeneous Wiener process model with an adaptive drift. IEEE Transactions on Reliability 2015; 64(2): 687-700, http://dx.doi.org/10.1109/TR.2015.2403433.

5. Gebraeel N, Elwany A Pan J. Residual life predictions in the absence of prior degradation knowledge. IEEE Transactions on Reliability 2009; 58(1): 106-117, http://dx.doi.org/10.1109/TR.2008.2011659.

6. Gebraeel N, Lawley M A, Li R, et al. Residual-life distributions from component degradation signals: a Bayesian approach. IIE Transactions 200; 37(6): 543-557.

7. Guida M, Penta F. A Bayesian analysis of fatigue data. Structural Safety 2010; 32:64-76, http://dx.doi.org/10.1016/j.strusafe.2009.08.001.

8. Jiang X M, Yuan Y, Liu X. Bayesian inference method for stochastic damage accumulation modeling. Reliability Engineering \& System Safety 2013; 111:126-38, http://dx.doi.org/10.1016/j.ress.2012.11.006.

9. Jin G, Matthews D E, Zhou Z. A Bayesian framework for on-line degradation assessment and residual life prediction of secondary batteries in spacecraft. Reliability Engineering \& System Safety 2013;113:7-20, http://dx.doi.org/10.1016/j.ress.2012.12.011.

10. Karandikar J M, Kim N H, Schmitz T L. Prediction of remaining useful life for fatigue-damaged structures using Bayesian inference. Engineering Fracture Mechanics 2012; 96:588-605, http://dx.doi.org/10.1016/j.engfracmech.2012.09.013.

11. Liao C M, Tseng S T. Optimal design for step-stress accelerated degradation tests. IEEE Transactions on Reliability 2006; 55: 59-66, http:// dx.doi.org/10.1109/TR.2005.863811.

12. Liao H, Elsayed E A. Reliability inference for field conditions from accelerated degradation testing. Naval Research Logistics 2006; 53(6): 576-587, http://dx.doi.org/10.1002/nav.20163.

13. Ling M H, Tsui K L, Balakrishnan N. Accelerated degradation analysis for the quality of a system based on the Gamma process. IEEE Transactions on Reliability 2015; 64(1): 463-472, http://dx.doi.org/10.1109/TR.2014.2337071.

14. Lim H, Yum B J. Optimal design of accelerated degradation tests based on wiener process model. Journal of Applied Statistics 2011; 38:309325, http://dx.doi.org/10.1080/02664760903406488.

15. Meeker W Q, Escobar L A. Accelerated degradation tests: modeling and analysis. Technometrics 1998; 40(2): 89-99, http://dx.doi. org/10.1080/00401706.1998.10485191.

16. Ntzoufras I. Bayesian Modeling Using WinBUGS: John Wiley \& Sons; 2009, http://dx.doi.org/10.1002/9780470434567.

17. Padgett W J, Tomlinson M A. Inference from accelerated degradation and failure data based on Gaussian process models. Lifetime Data Analysis 2004; 10:191-206, http://dx.doi.org/10.1023/B:LIDA.0000030203.49001.b6.

18. Park C, Padgett W J. Stochastic Degradation Models With Several Accelerating Variables. IEEE Transactions on Reliability 2006; 55: 379390, http://dx.doi.org/10.1109/TR.2006.874937.

19. Peng C Y, Tseng S T. Statistical lifetime inference with Skew-Wiener linear degradation models. IEEE Transactions on Reliability. 2013, 62(2); 338-350, http://dx.doi.org/10.1109/TR.2013.2257055.

20. Rigat F, Mira A. Parallel hierarchical sampling: A general-purpose interacting Markov chains Monte Carlo algorithm. Computational Statistics \& Data Analysis 2012; 56:1450-67, http://dx.doi.org/10.1016/j.csda.2011.11.020.

21. Santini T, Morand S, Fouladirad M, et al. Accelerated degradation data of SiC MOSFETs for lifetime and remaining useful life assessment. Microelectronics Reliability 2014; 54: 1718-1723, http://dx.doi.org/10.1016/j.microrel.2014.07.082.

22. Si X S, Wang W B, Hu C H, et al. Remaining useful life estimation - a review on the statistical data driven approaches. European Journal of Operational Research 2011; 213:1-14, http://dx.doi.org/10.1016/j.ejor.2010.11.018.

23. Si, X S, Wang W B, Hu C H, et al. Estimating remaining useful life with three-source variability in degradation modeling. IEEE Transactions on Reliability 2014; 63(1): 167-190, http://dx.doi.org/10.1109/TR.2014.2299151.

24. Thas O, Ottoy J P. Some generalizations of the Anderson-Darling statistic. Statistics \& Probability Letters 2003; 64:255-61, http://dx.doi. org/10.1016/S0167-7152(03)00169-X.

25. Wang L, Pan R, Li X, Jiang T. A Bayesian reliability evaluation method with integrated accelerated degradation testing and field information. Reliability Engineering \& System Safety 2013; 112:38-47, http://dx.doi.org/10.1016/j.ress.2012.09.015.

26. Wang H W, Xu T X, Mi Q L. Lifetime prediction based on Gamma processes from accelerated degradation data. Chinese Journal of Aeronautics 2015; 28(1): 172-179, http://dx.doi.org/10.1016/j.cja.2014.12.015.

27. Wang H W, Xu T X, Wang W Y. Remaining life prediction based on Wiener processes with ADT prior information. Quality and Reliability Engineering, http://dx.doi.org/10.1002/qre.1788.

28. Wang H W, Xu T X, Zhao J Z. Residual Life prediction method of fusing accelerated degradation and field degradation data. Acta Aeronautica et Astronautica Sinica 2014; 35(12):3350-3357.

29. Wang X. Wiener processes with random effects for degradation data. Journal of Multivariate Analysis 2010; 101:340-51, http://dx.doi. org/10.1016/j.jmva.2008.12.007.

30. Wang X L, Balakrishnan N, Guo B. Residual life estimation based on a generalized Wiener degradation process. Reliability Engineering and System Safety 2014; 124: 13-23, http://dx.doi.org/10.1016/j.ress.2013.11.011.

31. Whitmore G A, Schenkelberg F. Modelling Accelerated Degradation Data Using Wiener Diffusion With A Time Scale Transformation. Lifetime Data Anal 1997; 3:27-45, http://dx.doi.org/10.1023/A:1009664101413.

32. Yang Z, Chen Y X, Li Y F, et al. Smart electricity meter reliability prediction based on accelerated degradation testing and modeling. Electrical Power and Energy Systems 2014; 56: 209-219, http://dx.doi.org/10.1016/j.ijepes.2013.11.023. 
33. Ye Z S, Chen L P, Tang L C, et al. Accelerated degradation test planning using inverse Gaussian process. IEEE Transactions on Reliability 2014; 63(3): 750-763, http://dx.doi.org/10.1109/TR.2014.2315773.

34. Zaidan M A, Harrison R F, Mills A R, et al. Bayesian hierarchical models for aerospace gas turbine engine prognostics. Expert Systems with Applications 2015; 42:539-553, http://dx.doi.org/10.1016/j.eswa.2014.08.007.

35. Zhou Y Q, Weng C X, Ye X T. Study on Accelerated factor and condition for constant failure mechanism. Systems Engineering and Electronics 996; 18: 55-67.

\section{Hao-Wei WANG \\ Ke-Nan TENG}

Naval Aeronautical and Astronautical University

The second road, 188 Yantai, China

E-mail: 13705355730@139.com,wyg2010123@126.com 